Picton, S., S.L. Barton, M. Bouzayen, A.J. Hamilton, and D. Grierson. 1993. Altered fruit ripening and leaf senescence in tomatoes expressing an antisense ethylene-forming enzyme transgene. Plant J. 3:469-481.

Ranwala, A.P., C. Suematsu, and H. Masuda. 1992. Role of $\beta$-galactosidases in the modification of cell wall components during muskmelon fruit ripening. Plant Physiol. 100:1318-1325.

Rose, J.K.C. and A.B. Bennett. 1999. Cooperative disassembly of the cellulosexyloglucan network of plant cell walls: Parallels between cell expansion and fruit ripening. Trends in Plant Sci. 4:176-183.

Rose, J.K.C., H.H. Lee, and A.B. Bennett. 1997. Expression of a divergent expansin gene is fruit-specific and ripening-regulated. Proc. Natl. Acad. Sci. USA 94:5955-5960

Rose, J.K.C., K.A, Hadfield, J.M. Labavitch, and A.B. Bennett. 1998. Temporal sequence of cell wall disassembly in rapidly ripening melon fruit. Plant Physiol. 117:345-361.
Sakurai, N. and D.J. Nevins. 1993. Changes in physical properties and cell wall polysaccharides of tomato (Lycopersicon esculentum) pericarp tissue. Physiol. Plant. 89:681-686.

Schröder, R., R.G. Atkinson, G. Langenkämper, and R.J. Redgwell. 1998 Biochemical and molecular characterisation of xyloglucan endotransglycosylase from ripe kiwifruit. Planta 204:242-251.

Schuch, W., J. Kanczler, D. Robertson, G. Hobson, G. Tucker, D. Grierson, S. Bright, and C.R. Bird. 1991. Fruit quality characteristics of transgenic tomato fruit with altered polygalacturonase activity. HortScience 26:1517-1520.

Shani, Z., M. Dekel, G. Tsabary, and O. Shoseyov. 1997. Cloning and characterization of elongation specific endo- $\beta$-1,4-glucanase (cell) from Arabidopsis thaliana. Plant Mol. Biol. 34:837-842.

Tong, C.B.S. and K.C. Gross. 1988. Glycosyl-linkage composition of tomato fruit cell wall hemicellulose fractions during ripening. Physiol. Plant. $74: 365-370$.

\title{
Manipulation of Ethylene Synthesis and Perception in Plants: The Ins and the Outs
}

\author{
Harry J. Klee \\ University of Florida, Horticultural Sciences, POB 110690, Gainesville, FL 32611 \\ David G. Clark \\ University of Florida, Environmental Horticultural, POB 110670, Gainesville, FL 32611
}

The biological effects of ethylene on plant growth and development have been documented for over a century. Ethylene profoundly influences many aspects of development, both pre- and postharvest (Abeles et al., 1992). Spoilage losses ascribed to ethylene effects are significant for both food and ornamental crops. The major agricultural losses associated with ethylene have spurred research on methodologies for control of its synthesis and action. We have been particularly interested in two physiological processes associated with high economic value: fruit ripening and flower senescence. This article addresses biotechnological approaches to control these two processes. There are multiple strategies for controlling ethylene synthesis and response. We will limit our discussion to those with which we have personal experience. Although we will not cover all of the potential target genes, the strategies outlined here apply to the other gene targets.

Fruits in which ripening is controlled by ethylene are generally referred to as climacteric. Examples include tomato, melon, mango, papaya, and banana. Our efforts have focused on tomato as a model for several reasons. The tomato is relatively easy to genetically modify via Agrobacterium tumefaciens-mediated transformation. It has a broad base of physiological, biochemical, and genetic research on which to build. It is also a highly important commercial crop, being the number one valued vegetable produced in Florida (Lucier, 2000). Partly because of its economic importance, much research has been focused on the molecular biology of tomato ethylene synthesis and perception.

Like climacteric fruits, a subset of flowers produce and senesce in response to ethylene. One of the best understood of these species is petunia. A petunia flower will produce large amounts of ethylene within hours of pollination. Exposure of flowers to ethylene induces rapid loss of turgor that leads to corolla wilting within 1 to $2 \mathrm{~d}$. Like tomato, petunia is readily transformable and has an excellent foundation of genetic, physiological, and biochemical research. All of these factors make it an excellent model system for genetic manipulation.

\section{GENES INVOLVED IN ETHYLENE BIOSYNTHESIS}

Ethylene is synthesized from the common metabolic precursor $S$ adenosylmethionine (SAM). Synthesis of ethylene is a two-step pro-

Received for publication 29 Nov. 2001. Accepted for publication 30 Nov. 2001 Florida Agricultural Experiment Station Journal Series No. R-08732. This work was funded in part by a USDA/NRI grant to H.J.K., Monsanto Company, and the Fred C. Gloeckner Foundation. cess that is highly transcriptionally regulated. The limiting step is catalyzed by ACC synthase (ACS). This enzyme converts SAM to 1aminocyclopropane-1-carboxylate (ACC). That ACC is then converted by ACC oxidase (ACO) to ethylene. In all plants examined to date, ACS is encoded by a complex multigene family (Oetiker et al., 1997; Rottmann et al., 1991). There are at least 10 tomato genes encoding different ACC synthases. These genes are highly regulated and each is induced in a different way by various developmental or environmental cues (Oetiker et al., 1997). There are two specific ACS genes that are responsible for synthesis of all of the ACS enzyme made during tomato fruit ripening. These genes are positively regulated by ethylene. This regulation explains the autocatalytic synthesis of ethylene during tomato fruit ripening; a small amount of ethylene leads to a rapid and large increase in ethylene at the onset of ripening. Synthesis of ACC seems to be the most highly regulated step in ethylene synthesis. ACO is also somewhat regulated, also being ethylene inducible, but does not appear to be limiting under normal circumstances. In the tomato fruit, one of the four genes appears to encode most of the ACO enzyme.

Researchers have used biotechnological approaches to shut off synthesis of both ACC synthase and ACC oxidase with great success (Hamilton et al., 1990; Oeller et al., 1991). In tomato, antisense ACS and ACO gene expression leads to effective shut-off of the endogenous ripening-associated genes. Using this antisense strategy, ethylene synthesis has been blocked and fruits from these plants do not ripen.

An alternative strategy to antisense shut-off of endogenous genes involves expression of a gene encoding ACC deaminase. This enzyme degrades ACC to $\alpha$-ketobutyric acid, a precursor of branched chain amino acids (Klee et al., 1991). The gene encoding ACC deaminase was originally isolated from a Pseudomonas species isolated from soil. When the gene is expressed in a plant, the enzyme competes with ACO for ACC. If enough ACC deaminase is present, the plant will accumulate far less ACC.

\section{GENES INVOLVED IN ETHYLENE PERCEPTION}

In the last several years, great progress has been made in the area of ethylene perception and signal transduction (Bleecker and Schaller, 1996). The ability to make mutants that are insensitive to ethylene and then to clone the corresponding genes has led to identification of several genes that are essential for the ethylene signal to be perceived by plants. We have focused our attention on the first gene in the 
Arabidopsis thaliana pathway, ETR1 (Chang et al., 1993). This gene has been shown to encode the ethylene receptor (Schaller and Bleecker, 1995). From a biotechnology perspective, what is important is that mutations in ETR 1 cause dominant ethylene insensitivity. The mutant form of the gene that we have used is designated etr 1-1. This mutation abolishes ethylene binding to the receptor. A copy of the mutant gene, when introduced into a wild-type plant, makes that plant ethylene insensitive.

\section{DESIGNING A STRATEGY FOR GENETIC ENGINEERING}

In the design of a strategy for interfering with ethylene, there are multiple questions for a researcher to ask. These include:

- Do I wish to target ethylene synthesis or sensitivity?

- How much control do I want?

- What is the most straightforward way to achieve the goal?

The first question addresses the system and its needs. Does the plant tissue in question produce the ethylene or is it provided by an external source? This will depend on the process that we are attempting to control and how that process is regulated. Frequently, the offending ethylene is coming from outside the target tissue; the textbook case in postharvest physiology involves handling of lettuce. Many varieties of lettuce are susceptible to an ethylene-mediated disorder known as russet spotting. This disorder involves formation of brown spots on lettuce leaves, making the head visibly undesirable. The problem does not arise from endogenous ethylene, however. It is most often caused by improper storage or co-shipment of susceptible varieties of lettuce with ethylene-generating produce such as tomatoes. In such a case, targeting ethylene synthesis does not solve the problem. Only blockage of ethylene perception would be effective. Thus, the target must be the genes involved in ethylene signal transduction. In contrast, if the target tissue is a climacteric fruit, it is more logical to target ethylene synthesis. A fruit must eventually be ripened for sale, so it must be capable of responding to ethylene, either exogenous or endogenous. While it is possible to reduce ethylene response without eliminating it, control of ethylene synthesis is probably simpler. Thus, a thorough knowledge of the target organism and the commercial handling system is essential to develop an appropriate strategy for genetic engineering.

A related question concerns how much control is necessary for the product concept. As mentioned above, a climacteric fruit must be capable of ripening to be saleable. Thus, it needs to be capable of responding to ethylene. The ethylene may be produced internally or provided externally, depending on the degree of shut-off of ethylene synthesis. The product handling system will define which source of ethylene is most logical. For example, commercial producers and/or wholesalers of tomatoes and bananas routinely treat large quantities of fruit with ethylene gas to bring it to the proper stage of ripeness for sale. Repackers already employ sophisticated technology for manipulating the degree of ripeness to capitalize on market trends. In contrast, producers of tropical fruits like melons or mangoes do not routinely treat fruits with ethylene. In these situations, a fruit that will not ripen without exogenous ethylene may be less desirable commercially. Thus, the target for many fruits may be a product that has reduced ethylene synthesis to achieve longer shelf life but still produces enough ethylene to eventually ripen without extensive treatments. Unfortunately, the product concept may need to be defined experimentally; i.e., do I need to reduce ethylene synthesis by $90 \%$ or $98 \%$ ? Defining the target greatly impacts the technical approach to engineering ethylene control.

The answer to the final question concerning strategies is dependent on the above two questions as well as the available molecular tools. In terms of controlling ethylene synthesis, there are at least two approaches that we have used: antisense to endogenous ACS or ACO and expression of Pseudomonas ACC deaminase. Each of these approaches has distinct advantages and disadvantages. In the case of the antisense strategy, the greatest advantage is that it is possible to achieve almost complete elimination of ethylene synthesis in the target tissue/plant. Antisense (or the related co-suppression) technology has been successful in achieving 100\% reduction of endogenous ACS or ACO expression (Hamilton et al., 1990; Oeller et al., 1991). It should be noted that the technology determines what the maximal level of ethylene control will be. However, because of what is termed "position effect," a range of expression will be achieved in the independent transgenic events. Thus, a range of transgenic lines varying from $0 \%$ to $100 \%$ can be identified. When one does not know precisely what level of ethylene reduction best fits the production system, this range of expression is a distinct advantage. There are two significant disadvantages to the antisense technology, however. First, antisense technology is dependent on having the target gene in-hand. For example, a necessary precursor to shutting off ethylene synthesis in tomato fruit is to have access to the tomato ethylene biosynthetic gene(s). Related to the necessity of a gene in-hand is the knowledge of which gene is in fact the target for manipulation. Since tomato has at least 10 ACS genes and four ACO genes, this is not necessarily a trivial undertaking. In other words, a great deal of foundation research may be necessary before an appropriate strategy for genetic manipulation can be identified. This approach can be contrasted with the use of ACC deaminase. Since ACC deaminase, when expressed in plant tissue, degrades the immediate precursor of ethylene, it obviates the need for any prior knowledge of the endogenous ethylene biosynthetic apparatus. If the gene is expressed at a high enough level, the enzyme will effectively reduce ethylene synthesis, regardless of the plant or organ. The disadvantage of ACC deaminase, or any enzyme that targets destruction of an ethylene precursor, is that a competition is set up within the target cell. What determines the degree of ethylene reduction is the product of the affinity of the enzyme for its substrate and the amount of protein synthesized. In the case of ACC deaminase, the enzyme has low relative affinity for ACC in comparison to ACO; the Km for ACC of ACO is $\approx 20$-fold lower than that of ACC deaminase. This means in practical terms that ACO is a much better scavenger of ACC than ACC deaminase. Thus, to drive the reaction in the desired direction, substantially more ACC deaminase than ACO must exist in a cell. Fortunately, quite high expression of ACC deaminase can be achieved, but the best level of ethylene reduction that we have achieved in tomato with ACC deaminase is $\approx 90 \%$. If greater ethylene reduction is needed, an antisense strategy is required.

\section{TRANSGENIC PLANTS: ETHYLENE SYNTHESIS}

We have produced several hundred transgenic tomato lines that express antisense ACS, antisense ACO, or ACC deaminase. Based on analysis of these lines, we can make several conclusions. First, when the predominantly expressed genes can be identified and knocked out, an antisense strategy is highly effective for reducing ethylene synthesis to nearly undetectable levels. In our hands, antisense ACS or ACO lines that have $99 \%$ or greater reduction in ethylene could be obtained at a reasonable frequency ( $\approx 5 \%$ of transgenic events). Lines with at least $90 \%$ reduction in ethylene could be obtained at a much higher frequency (at least $25 \%$ of transgenic events). Analysis of many ethylene-inhibited lines indicated that tomato fruits with $90 \%$ or greater reductions in ethylene synthesis exhibited reproducible delays in ripening. Lines with $99 \%$ reductions never ripened without application of exogenous ethylene. In contrast, it was much more difficult to identify lines transformed with ACC deaminase that had significant delays in ripening. However, several such lines out of more than 500 were identified. No ACC deaminase line ever had more than $95 \%$ reduction in ethylene synthesis. Thus, lines that have significantly delayed ripening were much more easily obtained with an ACS/ACO antisense approach.

In terms of fruit ripening, tomato lines that had a wide range of delays in the time from breaker to full ripe were obtained with all three approaches. Clearly, an ethylene reduction strategy is capable of delivering a delayed ripening fruit. However, when these fruits were compared with the ripening inhibited (rin) mutant hybrids currently in widespread commercial production, the transgenic lines did not outperform the rin mutant. Thus, there is little incentive for commercial introduction of the transgenic varieties. Since rin hybrids are already in commercial production and provide the ability to harvest "vine ripe," it is highly unlikely that transgenic ripening-delayed fruits will be introduced into commercial production. Nonetheless, several varieties of ripening-delayed tomato have been approved for sale by U.S. government agencies, including one ACC deaminase line. 


\section{TRANSGENIC PLANTS: ETHYLENE PERCEPTION}

We have produced transgenic plants expressing the mutant form of the Arabidopsis ethylene receptor etr 1 -1. This mutation confers dominant and complete ethylene insensitivity when expressed in Arabidopsis. Initially, we asked the question whether the mutant form of the Arabidopsis receptor would work in a heterologous species. In order to answer this question, we transformed etrl-1, under the transcriptional control of the strong, constitutive cauliflower mosaic virus $35 \mathrm{~S}$ promoter, into several species. We were able to obtain transgenic tomato, petunia, and tobacco plants that had greatly reduced ethylene responsiveness (Wilkinson et al., 1997). We have also obtained transgenic cotton plants with reduced ethylene responses (T. Rangwala, C. Lashbrook, and H. Klee, unpublished). Thus, the Arabidopsis mutant gene is clearly capable of functionally interfering with ethylene perception in multiple species.

In each species we were able to control the target response. For example, in tomato, fruits did not ripen (Wilkinson et al., 1997). Phenotypically, the transgenic plants resemble the ethylene-insensitive mutant, Never ripe ( $\mathrm{Nr}$ ). In petunia, we sought to inhibit ethylene and pollination-induced flower senescence. Indeed, flowers of the transgenic plants did not wilt when exposed to exogenous ethylene. When pollinated, flowers of the transgenic lines lasted, on average, $4 \times$ longer than wild-type flowers (Wilkinson et al., 1997). These highly significant differences indicate great promise for the use of ethylene insensitivity for extending floral life.

\section{UNINTENDED CONSEQUENCES: THE DARK SIDE}

Although we have been able to control fruit ripening and ethylenemediated floral senescence, we are not yet at the point of commercial efficacy. Ethylene is a critical hormone that controls many aspects of growth and development. It is also an important signal that mediates many responses to environmental stimuli (Abeles et al., 1992). Thus, it is not entirely unexpected that alterations of ethylene synthesis and perception have unintended consequences on the survival of transgenic plants. We have seen two major effects that must be considered further.

Ethylene has a major role in the induction of a battery of defenserelated genes (Reymond and Farmer, 1998). For example, many of the genes associated with pathogen defense are known to be ethyleneinducible. This suggests that ethylene may have an important role in defense to pathogen attack. We have examined the responses of tomato lines that are ethylene insensitive or are unable to synthesize ethylene. We have observed that the ethylene-insensitive $\mathrm{Nr}$ mutant is actually more tolerant of several tomato pathogens (Lund et al., 1998). Specifically, we observed a large reduction in symptoms of plants infected with either Xanthomonas campestris pv. vesicatoria or Pseudomonas syringae pv. tomato. However, an ACC deaminase line was more susceptible to Fusarium crown rot (J. Shapiro, pers. comm.). Similarly, we have seen enhanced susceptibility of transgenic ethylene-insensitive petunia plants to normally nonpathogenic Botrytis (D. Clark and H. Klee, unpublished). A similar enhanced susceptibility of transgenic etr1-1 transgenic tobacco to Pythium has been reported (Knoester et al., 1998). Taken together, these results indicate the potential of enhanced disease susceptibility of transgenic ethylene-altered lines when the transgene is expressed constitutively throughout the plant.

A second area of caution is related to root formation. We initially observed a greatly reduced capacity of the ethylene-insensitive $\mathrm{Nr}$ tomato line to produce adventitious roots. When we tested a transgenic etr1-1-expressing petunia line, we observed the same effect (D. Clark et al., 1999). Ethylene insensitivity nearly abolishes the ability of stems to produce adventitious roots, and this cannot be overcome by applications of rooting hormones containing auxin. This result clearly establishes an essential role for ethylene responses in initiation of adventitious roots. While the inability to produce these roots is not necessarily a major problem in seed-propagated crops, it is clearly cautionary for application to horticultural species that are propagated by vegetative cuttings. If shoots are incapable of forming adventitious roots, this will present a major obstacle to commercialization. A related problem involves the actual production of transgenic plants. Most transformation systems involve a stage of tissue culture where synthesis of adventitious roots is essential. Our results would predict that it should be very difficult to produce transgenic plants with a high degree of ethylene insensitivity. In fact, this is the case. We observe a very low frequency of transgenic events that are highly ethylene insensitive. It is likely that the inability to regenerate properly selects against the strongest ethylene-insensitive events. Finally, it should be noted that a plant that is compromised in its ability to produce adventitious roots may not be as vigorous in a field setting. For example, tomato plants typically produce many adventitious roots. In the case of damage to the root system, adventitious roots can help the plant to compensate. Indeed, this may be why ACC deaminase lines exhibit enhanced susceptibility to Fusarium crown rot, a pathogen that initially enters the plant through the roots and destroys them.

\section{A SOLUTION?}

Overall, we have determined that inhibition of ethylene synthesis or perception can be an effective tool for controlling many aspects of plant development. Fruit ripening can clearly be controlled in a manner that extends useful shelf life. Indeed, if not for the rin mutant, transgenic tomato fruits would likely be in widespread use today. What the results to date illustrate is that the technology can be effective in species where no comparable rin mutant exists. Thus, many of the short-lived tropical fruits like mango, papaya, and banana are obvious desirable targets of the technology. Similarly, the effective life of many flower species can be greatly extended by engineering ethylene insensitivity, eliminating the need for chemical treatments. It is also clear that constitutive expression of transgenes is not likely to be the solution. What is needed is the directed expression of transgenes to the desired target tissues. Expression will need to be directed via appropriate transcriptional promoters to fruits or flowers. Fortunately, many potentially useful promoter candidates are already described in the literature. Through reiterative efforts, it is likely that commercially desirable transgenic plants will be available within the next several years.

\section{Literature Cited}

Abeles, F.B., P.W. Morgan, and M.E. Saltveit. 1992. Ethylene in plant biology. Academic Press, San Diego.

Bleecker, A.B. and G.E. Schaller. 1996. The mechanism of ethylene perception. Plant Physiol. 111:653-660.

Chang, C., S.F. Kwok, A.B. Bleecker, and E.M. Meyerowitz. 1993. Arabidopsis ethylene-response gene ETRI: Similarity of products to two-component regulators. Science 262:539-544.

Clark, D.G., E.K. Gubrium, H.J. Klee, J.E. Barrett, and T.A. Nell. 1999. Root formation in ethylene insensitive plants. Plant Physiol. 121:53-59.

Hamilton, A.J., G.W. Lycett, and D. Grierson. 1990. Antisense gene that inhibits synthesis of the hormone ethylene in transgenic plants. Nature 346:284-287.

Klee, H.J., M.B. Hayford, K.A. Kretzmer, G.F. Barry, and G.M. Kishore. 1991 Control of ethylene synthesis by expression of a bacterial enzyme in transgenic tomato plants. Plant Cell 3:1187-1193.

Knoester, M., L.C. Van Loon, J. Van Den Heuvel, J. Hennig, J.F. Bol, and H.J.M. Linthorst. 1998. Ethylene-insensitive tobacco lacks nonhost resistance against soil-borne fungi. Proc. Nat. Acad. Sci. USA 95:1933-1937.

Lucier, G. 2000. Fresh-market tomato industry trends. Tomato Mag. 4(4):6-16.

Lund, S.T., R.E. Stall, and H.J. Klee. 1998. Ethylene regulates the susceptible response to pathogen infection in tomato. Plant Cell 10:371-382.

Oeller, P.W., L. Min-Wong, L.P. Taylor, D.A. Pike, and A. Theologis. 1991. Reversible inhibition of tomato fruit senescence by antisense RNA. Science 254:437-439.

Oetiker, J., D. Olson, O. Shiu, and S.F. Yang. 1997. Differential induction of seven 1-aminocyclopropane-1-carboxylate synthase genes by elicitor in suspension cultures of tomato (Lycopersicon esculentum). Plant Mol. Biol. 34:275-286.

Reymond, P. and E.E. Farmer. 1998. Jasmonate and salicylate as global signals for defense gene expression. Current Opinion in Plant Biol. 1:404-411.

Rottmann, W.H., G.F. Peter, P.W. Oeller, J.A. Keller, N.F. Shen, B.P. Nagy, L.P. Taylor, A.D. Campbell, and A. Theologis. 1991. 1-aminocyclopropane-1carboxylate synthase in tomato is encoded by a multigene family whose transcription is induced during fruit and floral senescence. J. Mol. Biol. 222:937-961

Schaller, G.E. and A.B. Bleecker. 1995. Ethylene binding sites generated in yeast expressing the Arabidopsis ETRI gene. Science 270:1809-1811.

Wilkinson, J., M. Lanahan, D. Clark, A. Bleecker, C. Chang, E. Meyerowitz, and H. Klee. 1997. A dominant mutant receptor from Arabidopsis confers ethylene insensitivity in heterologous plants. Nature Biotech. 15:444-447. 